\title{
The Empirical Analysis of Performance Management System : A Case Study of a University in South Africa
}

\author{
Bethuel Sibongiseni Ngcamu \\ Mangosuthu University of Technology, South Africa \\ ngcamub@mut.ac.za
}

\begin{abstract}
The absence of a single performance management system (PMS) aligned to institutional strategic plan often results in failure to deliver anticipated outcomes. This study aims to investigate the employees' readiness on the forthcoming implementation of the PMS at the university concerned and diagnose impediments, thus providing pertinent recommendations on the bottlenecks identified.It is a great concern that universities fail to develop customised performance management systems which are aligned to university strategic plans that can be cascaded to faculties and departments.This study adopted a quantitative survey method, whereby a structured questionnaire was administered by the researcher to a selected population size of 150 of which 108 completed questionnaires generating a response rate of $72 \%$. A reasonably high percentage $(34.3 \%)$ of the respondents disagreed with the need for PMS in this university and a disproportionately high percentage of $49.1 \%$ of the respondents agreed that there is a dire need for such as the system will manipulate and enforce a particular agenda in its absence.The article presents an overview of factors that have a potential to hamper the successful implementation of the PMS in universities. The findings arrived in this study can inform and assist university leaders to consider all contributory factors on the ineffectivess of the PMS in universities during their planning phases.
\end{abstract}

Keywords: University of technology, performance management system, reward strategies, effectiveness

\section{Introduction}

At South African universities, performance management systems are more or less obsolete as a result, there is little or no accountability of staff with regard to their performance which makes it difficult to be able to measure the university's overall performance in relation to its strategic objectives. Performance management deals with the challenge organizations face in defining, measuring and stimulating employee performance with the ultimate goal to improve organizational performance (Hartog, Boseli \& Paauwe, 2004: 2).Thus, the failure of the system is exacerbated by factors such as strategic objectives that are not cascaded down to the level of employees, unfair and unequal systems on which remuneration and reward is based (Burney, Henle \& Widener, 2009 and Chan, 2004), absence of continual feedback (Matunhu \& Matunhu, 2008), inadequate internal communication, and unrealistic expectations in terms of rewards (Brennan \& Shah, 2000). However, a number of commentators, especially those within the education sector, regard this managerialistic approach to performance appraisal as unwarranted, counter productive (Scholtes, 1999) and unworkable and unacceptable in knowledge-based organisations (Simon, 2001). Other authors describe it as antithetical to a self-governing community of professionals, an infringement of academic freedom, based on a top-down approach to research and teaching which severely restricts creativity and self-development, or a covert means of introducing greater governmental control of the Higher Education and Further Education sectors and increasing the remuneration of those who work in them (Barry, Chandler \& Clark, 2001, Henson, 1994).

This study intends to answer whether the PMS will will be consistently used and implemented throughout the university concerned. Furthermore, the main objective of this study was to investigate the employees' readiness on the forthcoming PMS in terms of their expectations, impacts, consistencies and implementations thereof.Due to the paucity of studies conducted to establish the causes of failures of the PMS, employees expectations, consistent use and its implementation in universities, the importance of the present study cannot be underestimated. There is limited knowledge regarding the actual mechanisms which underlie the positive effects of performance management (PM) in organisations (Bourne, Kennerley, Franco-Santos, 2000 and Bourne, Mills, Wilcox, Mweemba \& Malan (2009). This study will contribute to the body of knowledge in South African higher education institutions, since to date no one had written about the aforementioned variables. This article presents the literature synopsis on performance management dimensions followed by research findings, results and recommendations flowing from this study. 


\section{Theoretical Orientation}

Employees' expectations and feedback on PMS: Failure to link job descriptionsto departmental strategic plans and those of the institution lead to weaknesses and under-performance as job description clearly describes activities and desired performance required of an employee. Fullan \& Scott (2009: 37) assert that misalignment problem such as the failure of individual position descriptions, performance plans, accountability, and reward and staff development systems to focus on the capabilities and priorities for effective deliverycontributenegatively to the core activities of the institution.Chan(2005: 145) argues that performance planning involves defining job responsibilities and setting performance expectations, goals or objectives at the beginning of the review period.According to Armstrong (1999), performance management emphasizes the integration of organizational objectives with individual goals, the on-going monitoring of performance, and training and development. Furthermore, Armstrong (2001: 191) asserts that both parties in the performance management process will also need guidance and training in the use of competencies, the preparation of performance agreements and plans, the preparation for and conducting of perfomance reviews, ratings and the completion of review forms. Competencies are factors contributing to high levels of individual performance, and therefore, organizational effectiveness (Armstrong, 1999).

Bernthal, Rogers \& Smith (2003) contend that performance management programs also provide a unique mechanism for on-going feedback and development, a critical component of engagement. After setting goals together, managers and employees can track progress and ensure that performance stays in alignment with goals and changing work conditions. Research conducted within the South African higher education system by Wilkinson, Fouries, Strydom, Van der Westhuizen \& Van Tonder (2004) reveal that successful performance management models in higher education institutions are achieved because strategic goals are cascaded down to the level of the individual employee and manifest in workload agreements with staff. Continuous feedback facilitates performance by helping employees to refocus their behaviour when they get off track. Performance management is seen as an integrated process in which managers work with their employees to set expectations, measure and review results, and reward performance, in order to improve employee performance, with the ultimate aim to positively affect organizational success (Mondy, Noe \& Premeaux, 2002). During performance reviews, managers can provide more specific feedback relative to goals to help employees identify strengths and areas for development. In this way, new performance goals can be set to leverage employee strengths and provide opportunities to address developmental or career goals. Armstrong (2001) believes that some of the skills and procedures, such as providing feedback, coaching, counselling and rating will be practised by managers so that subordinates are fully aware of the expected duties and responsibilities.

Impact of PMS on effectiveness and feedback clarification: There is little evidence that PMS can accomplish organisational/team/individual objectives, which in turn can make a positive contribution to organisational effectiveness, as there is little clarity about what practices make a PMS effective in universities. The process of measuring and subsequently actively managing organizational and employee performance in order to improve organizational effectiveness is currently seen as critical to the development and survival of organizations (Hartog, Boseli \& Paauwe, 2004). There are objectives that need to be accomplished by organisations, which include motivating performance, helping individuals develop their competencies (Maybodi, 2010), building a performance culture (Cameron \& Quinn, 1999), determining who should be promoted, eliminating individuals who are poor performers and helping implement organisational strategies. Edward (2003) reveals considerable research which shows that performance management effectiveness increases when there is ongoing feedback, behaviour-based measurements are used and trained raters are employed. However, there is one potential determinant of PMS effectiveness, that has received relatively little attention: how closely the results of the PMS are tied to significant rewards. Whilst, different empirical studies have been conducted on job satisfaction and its link to rewards (Probst \&Brubaker, 2001), rewards as a tool to promote effectiveness of employees (Hinkin \& Schriesheim, 2004) and enhancing participation and effective commitment (Travaglione \& Marshal, 2006). Franco-Santos, Lucianetti \& Bourne (2012) suggest that the performance management system must be supported by an effective communication mechanism that encourages feedback, dialogue, and participation. Decoene \& Bruggeman (2006) suggest that the use of performance management systems to influence monetary rewards can negatively affect motivation if the performance measures used have low strategic alignment, controllability, timeliness, and technical validity. 
The inconsistencies and paradoxies of the PMS: The most effective performance management systems are characterized by their consistent use throughout the organisation, their integration into approved policies, processes, key stakeholders and other mandates such asthe organisation-wide strategy. Misalignment, inconsistencies and lack of consensus at various levels of the organisation (Meybodi, 2010: 1); strategy not being implemented (Kaplan \& Norton, 1996 and Meekings, 1995); strategy not being linked to departmental, team and individual goals (Schneiderman, 1999) have been cited as contributory factors on the PMS failure in organisations. Several researchers such asBernthalet al. (2003), Oakes (2007) and Armstrong (2009) have suggested that the main causes of the failure of the performance management system are lack of leadership and resistance to change.

Implementation of the PMS: Universities in developing countries are facing challenges in implementing performance management systems due to the fact that key stakeholders are not fully consulted, leading to resistence towards the system caused by fear of the unknown and mistrust towards it. Phiri (1998) has warned that an effective system of performance management is not easy to implement, and that it often impacts negatively on motivational levels of educators, especially in the South African context. The perception in these cases is that performance management is first and foremost a management tool aimed at stricter supervision. Different authors have raised various causes of PMS implementation failure as De Waal (2007) highlights lack of rewards for good performance, low political commitment by top officials, absence of training, cultural issues, international weaknesses, highly bureaucratic management systems; organisation interference, and lack of expertise to design sophisticated performance management systems (Mandonca \& Kanongo, 1996). Walwy (2008) argues that performance management of higher education institutions (HEIs) is a controversial and complex undertaking for a number of reasons, including the difficult environment within which these institutions operate, the long time periods over which their impact must be measured and the multiplicity of their objectives.

During implementation, PMS project leaders, who are mostly external consultants, encounter resistence from university stakeholders including employees or employee organisations and managers(Ngcamu, 2012: 1397). Various authors have suggested obstacles to the implementation of the PMS emanating from resistence to the measures (Bourne, Mills, Wilcox, Neely \& Platts, 2000), resistence from within and lack of cause-effect relationship among strategies (De Waal \& Counet, 2009); resistence to change (Karuhanga, 2010) and cultural resistance (Allen-Ile, Ile \&Munyaka, 2007). The negative effect of excessive use of consultants who are working in silos with existing staff members in designing institutional structures and policies, as well as PMS policies and procedures which lack ownership and consistency cannot be overestimated (Ngcamu, 2012). Furthermore, unregulated promotions, nepotism and corruption (Matunhu \& Matunhu, 2008)as well as political deployment in universities are some of the causes of the failure of PMS, as deployees fail to take concrete decisions as they consult their political masters who are mostly academically illiterate. Ngcamu (2012) argues that "politically incorrect" deployees are appointed to serve to university Councils and who often fail to understand the council's mandate of governance, but who interefere on operational issues favouring politically inclined key stakeholders either union(s) or student representatives or both.

\section{Methodology}

Research approach: The present study is based onthe quantitative research design, whereby descriptive statistics, namely measures of central tendency and measures of dispersion, were used to describe the distribution of scores on each variable and to determine whether the scores on different variables are related to each other. In this study, a survey research method was adopted which addressed the dimensions of the PMS in terms of its expectations, impact on effectiveness, consistent use and implementation thereof. The primary and secondary data was utilised to elicit information on the PMS. Saunders, Lewis and Thornhill (2007) indicate that primary literature sources include reports, thesis, government publications and the secondary sources of literature as encapsulating books, journals, newspapers and some government publications.

Research participants and sampling procedure: This quantitative study adopted a stratified random sampling and the university employees were identified as the total population. Underhill and Bradfield (1998) confirm that stratification is useful when the population is composite in nature, and can be divided into sub-populations that are distinct in characteristics of interest. The employees of the university concerned were divided into three categories, namely, academic, academic support and administration support. A structured questionnaire in a paper format was administered by the researcher 
to a population size of 150 as per Sekeran's (1992) recommended population size. Of the selected scientific sample, 108 completed the questionnaire generating a response rate of $72 \%$ which was used for the final analysis of this study. The high response rate was caused by the nature of the study conducted which was based on PMS which is topical in universities in this epoch which attracted the respondents to have an interest to fill the questionnaires.There were 50\% males and females respectively who responded, wherein, $64.4 \%$ of males and female respondentswere between the ages of 25-44 years. Of this $21.3 \%$ were females and males (18.5\%) who were between 25-34 years. Nearly half of the respondents (47.2) had postgraduate qualifications. It was observed that by gender, there were no significant differences (male-24.1\%) and (female-23.1\%) in the number of respondents having the same qualification.

Nearly $15 \%(14.8 \%)$ of the respondents had a postgraduate qualificationwhowere between the ages of 25-34 years. Of the sample $25.9 \%$ were academics, $22.2 \%$ academic support and $51.9 \%$ were administration support. Most $64.8 \%$ were at non-management level, $15.7 \%$ at junior management, $14.8 \%$ at middle management and $4.6 \%$ at senior management. Of all the senior managers, $40 \%$ had a tenure for at least 20 years. Half of this (20\%) was for Academic Managers and the other half for Administration Support Managers. Amongst the description for job type, Administration Support Managers comprised $25 \%$ of the respondents. When looking at tenure, this group made up $50 \%$ of the respondents. One major aspect of precision (reliability) were used in this study to ensure that the researcher used the appropriate instrument to produce consistent results. Reliability was computed by taking several measurements on the same subjects, the Cronbach's Coefficient Alpha values for individual dimensions were high and a reliability coefficient of 0.954 indicating a high degree of acceptable, consistent scoring for the different categories for this research. The sampling approach was considered relevant because this study is empirical and its aim is to assess the readiness of employees in relation to their perceived impact of PMS on effectiveness, consistent use and implementation thereof. The questionnaire was piloted to ten employees with the aim of identifying any errors, as well as testing the perceived reliability of the questionnaire.The reliability was confirmed as it had a high coefficient of 0.70 and above which was considered acceptable.

Measuring instruments: A self-developed structured questionnaire using a five-point Likert scale was developed to assess the key dimensions of PMS(current expectations for the PMS, current perceptions on the PMS impact on effectiveness, current perceptions on the impact of the PMS and implementation of the PMS). The five-point scale ranging from (1) strongly disagree, (2) disagree, (3) undecided, (4) agree to (5) strongly agree, was used. The Likert scale was used as it enables certain arithmetical operations to be performed on the data collected from the respondents and it also measures the magnitude of the differences among the individuals.

Research procedure: This study used a structured questionnaire which was administered by the researcher to a population size of 150 within the university concerned. Data was collected immediately after obtaining ethical clearance from the university authorities.

\section{Results}

Statistical analysis: The data collected from the respondents was analysed using Predictive Analytic Software (PASW) Statistics version 18.0 for data capturing, presentation, analysis and interpretation. Descriptive statistics were used for data analysis and interpretation. Descriptive and inferential statistics were used to analyse the data. The results were presented in the form of a table and narrative. As far as the PMS dimensions are concerned, current expectations for the PMS (Alpha =.834), current perceptions of the PMS impact on effectiveness (Alpha $=.907$ ), consistent use of the PMS (Alpha $=.909$ ) and implementation of the PMS (Alpha $=.886$ ) with an overall reliability score of 0.954 indicating a high degree of acceptability and consistency of the results. The questionnaire the researcher developed for this study consisted of five sections. Section A contained biographical data about age, gender, education, tenure, job type and current job level. Section B (10 sub-dimensions) aimed to gauge employee's perceptions on their expectation and the need for the PMS at the university concerned. An example of a sampled sub-dimension was 'PMS is needed in my organisation'. An example of the response scale was 'the disporportionately high percentage of $34.3 \%$ who disagreed, $21.3 \%$ who were undecided and $44.4 \%$ who agreed that PMS is needed in this organisation. 
Section C contained 8 sub-dimensions aimed to identify employee's perceptions on the PMS impact on efficiency and effectiveness. Overall, $78 \%$ of the respondents agreed with the sub-dimensions on average, with 5\% disagreeing.Section D (8 sub-dimensions) aimed to identify the impact of PMS. An example of a sub-dimension was 'In my organisation PMS will not be used to manipulate and to enforce a particular agenda'. The respondents showed the low percentage of disagreement (15.7\%) and uncertainty (35.2\%) pertaining to the latter subdimension and with $49.1 \%$ who agreed. Section E (10 sub-dimensions) aimed to identify employees perceptions on the implementation of the PMS. An example of the sub-dimension was 'I foresee PMS supported by the trade union'. Less than half of the respondents (42.6\%) believed that the PMS will be accepted by employees as $27.7 \%$ disagreed and $29.6 \%$ were undecided.

Descriptive statistics: The respondents were required to respond to the terms of the leading statements of the key dimensions of the study using a 1 to 5 Likert scale.

Table 1: Descriptive statistics - key dimensions of PMS

\begin{tabular}{lllll}
\hline Statistic & $\begin{array}{l}\text { Current } \\
\text { expectations } \\
\text { for the PMS }\end{array}$ & $\begin{array}{l}\text { Current perceptions } \\
\text { on the PMS impact } \\
\text { on effectiveness }\end{array}$ & $\begin{array}{l}\text { Current perceptions } \\
\text { on } \text { the of the PMS } \\
\text { consistent }\end{array}$ & $\begin{array}{l}\text { Implementation } \\
\text { of the PMS }\end{array}$ \\
\hline Mean & 3.9204 & 4.0694 & 3.7025 & 3.7490 \\
Median & 4.0000 & 4.1250 & 4.0000 & 3.8889 \\
Standard. Deviation & .63552 & .69025 & .82593 & .78851 \\
Variance & .404 & .476 & .682 & .622 \\
Minimum & 2.00 & 1.00 & 1.00 & 1.00 \\
Maximum & 5.00 & 5.00 & 5.00 & 5.00 \\
\hline
\end{tabular}

The study findings indicate that the mean score values indicate that employees have different views on the sub-dimensions of the PMS, which is in descending level based on mean scores, which are as follows:

- Current perceptions on the PMS impact on effectiveness (Mean $=4.0694)$.

- Current expectations for the PMS (Mean = 3.9204).

- Implementation of the PMS (Mean = 3.7490).

- Current perceptions on the consistent use of the PMS (Mean =3.7025).

Current expectations of the PMS: A frequency analysis was conducted and the findings of the study revealed that $34.3 \%$ of the respondents disagreed and $21.3 \%$ were undecided that PMS is needed within the university concerned. Meanwhile, $6.5 \%$ of respondents disagreed and $25.0 \%$ were undecided that performance plans will be aligned to the university goals. It is also noted that $74.1 \%$ of respondents have a definite view regarding the question of whether PMS will further and support organisational culture change, while $5.6 \%$ disagreed and $20.4 \%$ were undecided that PMS will improve interpersonal relations. With regard to non-monetary rewards, $11.1 \%$ disagreed and $27.8 \%$ were undecided that the system will provide this type of reward.

Current perceptions of the PMS's impact on effectiveness: Under the ambit of the current perceptions of the impact of the PMS on effectiveness, a frequency analysis was undertaken, showing that $7.4 \%$ of respondents disagreed and 25\% were undecided that PMS expectations will be clarified and individual performance feedback will be based on mutual understanding. Whereas, $10.2 \%$ disagreed and $24.4 \%$ were undecided that there would be an open dialogue between evaluators and those evaluated. Furthermore, $7.4 \%$ of the respondents disagreed, $21.3 \%$ were undecided and $4.6 \%$ disagreed that line managers will provide guidance. A total of $16.7 \%$ of respondents were undecided that employees will be measured according to the functions as stated in their job descriptions.

Consistent use of the PMS: The consistent use of the PMS is another aspect that requires thorough improvement as indicated by the study findings. A frequency analysis was undertaken and the research findings reflected that $14.8 \%$ of the respondents disagreed and $33.3 \%$ were undecided regarding the statement that PMS will be implemented consistently in this university. At the same time, $13.0 \%$ disagreed and $22.2 \%$ were undecided in response to the statement that PMS will address unfairness amongst employees. However, $20 \%$ of the respondents disagreed, $35 \%$ were undecided and $45 \%$ agreed that this system will address fairness in this organisation. The research findings further reveal that $16.7 \%$ of the respondents disagreed and $25.0 \%$ were undecided that PMS will result to equal workload 
distribution. A percentage of $9.3 \%$ of the respondents disagreed and $25.0 \%$ were undecided in response to the statement that the PMS will capacitate employees through training. The respondents do not believe (as supported by the research findings that 15.7\% disagreed and $35.2 \%$ were undecided) that PMS will not be used to manipulate employees and enforce a particular agenda. The findings show that $13.9 \%$ of the respondents disagreed and $37.0 \%$ were undecided that rewards will be openly and fairly distributed to those who are most deserving on the basis of effort, merit and results.

Implementation of the PMS: This dimension covers the leading statements on the PMS implementation including policy and procedures availability, commencement of the system, pilot project, incentives availability, perceived successes, resistence, support from the trade unions, anticipated working relationships and measurements tools. The latter subdimensions generated a reliability coefficient of .886 which was considered acceptable. The implementation of the PMS requires strategic improvement as displayed by the respondents on the execution of this system. The high percentage of $13 \%$ of the respondents disagreed and $34.3 \%$ were undecided regarding the statement that PMS will be implemented successfully at this university. The study results indicate that $9.3 \%$ of the respondents disagreed and a disproportionately high percentage of $35.2 \%$ were undecided that the PMS policy and procedures will be enacted. In addition, $11.1 \%$ disagreed and $29.6 \%$ were undecided that the PMS process will commence in 2012. However, $9.3 \%$ of the respondents disagreed and $22.2 \%$ were undecided that PMS project should commence to senior management by 2012. Hence, $27.8 \%$ of the respondents disagreed and $29.6 \%$ were undecided that PMS will never encounter any resistance. Amongst those respondents with degree qualifications, $15 \%$ disagreed, $20 \%$ were undecided and $65 \%$ agreed with this statement. The study shows that $13.5 \%$ of the respondents disagreed and $21.3 \%$ were undecided that the PMS will be supported by the trade union.

Discussion: The mean score values displayed in Table 1 reflect that on a scale from 1 to 5 , the respondents were between 4.0694 and 3.7025. This indicates that a high proportion of employees ranged from agree to undecided on statements relating to each dimension. These averages reflect the current status quo at the university concerned as there are institutional changes taking place, as well as the fear of the unknown as the PMS is regarded as a threat.The main objective of this study is to investigate the readiness of employees on the implementation ofthe PMS at the university concerned.Having reviewed the literature in the previous sections of this study, and statistically presented and analysed the findings of the perception study on the PMS within the university concerned, a discourse is essential to determine the correlation between the literature and research findings. The descriptive statistical results indicated an average mean value of 4 , indicating that there is a need for consideration and improvement on the dimensions of PMS. The high proportion of respondents who either disagreed or were undecided means that there is a need for an improvement plan focusing on communication and change management interventions visible to all categories of employees.

Current expectations for the PMS: Even though there is not much conclusive or empirical evidence on resistance(Bernthal et al., 2003), Oakes, 2007) and Armstrong, 2009)to the application of PMS to institutions of higher learning, such perceptions may emanate from the previous failed initiatives of PMS projects at well established and well resourced universities, as well as poor knowledge and understanding of the PMS's impact and benefits to organisations. The observations in this study are reminiscent of studies by Cameron \& Quin (1999) and Rose, Kumar \& Ling (2008), who examine the positive relationship between good organisational culture and performance. The findings of this study revealed that $27.8 \%$ of the respondents were undecided with regard to non-monetary rewards. Different authors and successful organisations have learnt that money is not the only compensation strategy to fulfil the needs of employees (see Harte, 1995; Hinkin \& Schriesheim, 2004 and Scott-Ladd, Travaglione \& Marshall, 2006).

Current perceptions of the PMS's impact on effectiveness: This dimension indicates a high mean score value of four (4) which shows that the respondents are in favour of the impact of the PMS on effectiveness(Hartog et al. 2004) in terms of achieving the agreed objectives or standards. Thus, this study supports the findings of Edward (2003) that performance effectiveness increases when there is ongoing feedback. Franco-Santos et al. (2012)suggest that effective communication mechanism that encouraging feedback increases performance effectiveness. Such findings have been confirmed by the present research findings indicating that $67.6 \%$ agreed with this sub-dimension even though there is a high percentage of respondents who were undecided, which leaves significant room for improvement. 
This study produced certain findings which were not consistent with previous studies. These include the highly disproportionate $65.7 \%$ of respondents who agreed that there would be an open dialogue between evaluators and those evaluated. On the other hand, the high percentage of $24 \%$ of the respondents who were undecided requires further consideration and attention to building trust by ensuring the impartiality and transparency of this system.Futhermore, $71.3 \%$ agreed on the PMS knowledgeability role the line managers will play during the duration of the project, which confirms the findings of authors such as Armstrong (2001), who discussed the role to be played by managers in the PMS process. Much room of improvement is indicated for the sub-dimension that employees will be measured against job descriptions. While $78.7 \%$ agreed, the fact that $16.7 \%$ were undecided and $4.6 \%$ disagreed raises serious concerns which are confirmed by Fullan \& Scott (2009).

The inconsistences of the PMS: The disproportionately high percentage of the respondents who have either disagreed or undecided about the sub-dimension of the study that states the PMS will be applied consistently throughout the university was synonymous with studies conducted by Meybodi, (2010) who established the causes of PMS failure due to misalignment and inconsistencies in its application. The low $3.8 \%$ difference of employees who agreed and those who disagreed and those who were undecided with the consistent use of the PMS justified the perceived mistrust amongst employees and management of the university. The research findings are consistent with earlier work that has examined the causes of the PMS failures (De Waal, 2007). Even though there is not enough empirical or scientific evidence that reflects a possible relationship between PMS in addressing fairness, this study did indicate a highest percentage of the respondents who disagreed and undecided about the role of the PMS on the fairness amongst the employees. The findings show that highest percentage of the respondents who either disagreed or undecided about the university offering training is in support of the studies conducted by Ohmeng (2009) who identified different causes of implementation failure as the absence of training. However, $65.7 \%$ of employees who agreed that such trainings are permissible proves the capabilities of the university concerned and its compliance to the Skills Development Act of 1998 (Act 97 of 1998) and Skills Levies Act of 1998 (Act 9 of 1998).

Implementation of the PMS: The study findings confirm findings of similar studies that have confirmed and emphasised the negative perceptions of employees regarding implementation of the PMS, who raised insconsistencies of the system and resistance to it as the main causality (De Waal \& Cournet, 2009; Maybodi, 2010; and Matunhu \& Matunhu, 2008). The perceptions of employees also embody past experiences as the research findings indicate a high percentage of employees who disagreed or were undecided about the need of the PMS policy and its procedures.Furthermore, the disproportionately high percentage of employees who were undecided and disagreed that the PMS will commence in 2012 and be piloted to senior management indicates the low confidence by the employees that the university is capable of implementing initiatives and projects successfully having been arleted in advance about the implementation of the system. There is a paucity of literature on the timing and duration of the implementation of the PMS. The high percentage of employees who disagreed $(27.8 \%)$ and who were undecided (29.6\%) that this system will never encounter any resistence. These results are consistent with earlier work as quoted from the literature about the importance of considering the union before implementing performance based rewards (Beavis, 2003). Furthermore, these findings are generally in agreement with studies conducted by Borne et al., (2000), Karuhanga, (2010) and Allen-Ile et al. (2007) who concur that the causes of failure of PMS implementation emanate from resistance to performance managementmeasures, inconsistencies of the system and resistance to change. The research findings of this study will prepare and equip human resources managers with strategies on how to avoid turbulence during PMS implementation and how to respond to inconsistencies which might occur within the university environment. Furthermore, this study will impact positively to the human resources managers on measuring performance that is cascaded from the university strategic plan.

\section{Conclusion}

This study arrives at a conclusion that for PMS to be effectively implemented, a flexible PMS needs to be designed in order to accomodate all employees at all levels. It futher recommends that in order for the PMS to improve effectiveness amongst employees; well crafted job descriptions in line with departmental strategic plans that are aligned with the comprehensive organisational strategy, need to be brought to light. A noteworthy finding of this study is that the majority of the respondents either disagreed or were undecided about the need of the PMS, which creates a never-ending search for the factors underpinning theirindecisiveness. It further stresses the crucial role that should be played by line managers,as it 
became apparent that the poor employee-employer relationships emanating from lack of trust were a major issue.The university thus, needs to design and implement change management interventions inclusive of management development programmes for line managers specifically that will focus on PMS. Compensation strategies for the PMS should be designed after thorough consultation with other key stakeholders like trade unions,in order to avoid resistance thereto and negative perceptions thereof. The university should endevour to utiliseresources at hand in designing and implementing the PMS and aim to minimise the use of external consultantsas this leads to lack of continuity, sustainability,ownership and consistency, and exercebates resistance amongst employees. This article contributes to the discussion of PMS strategies that should be taken into consideration by universities in implementing the PMS. Future research is still required to identify the extent to which the PMS is implemented inall universities in South Africa and the challenges faced by different universities whose pool of expereinces can inform improvements and overall effectiveness through the PMS.Furthermore, future research could explore communication appropriateness and knowledgeability of the line managers that can only improve the implementation of PMS and its overal impact.

\section{References}

Allen-Ile, C. O. K., Ile, I. U. \& Munyaka, S. A. (2007). Public sector employees' perception of performance management systsem's influence on career development. Journal of Public Administration, 42(4), 403-413.

Armstrong, M. (1999). Human resource management practice. London: KoganPage.

Armstrong, M. (2001). Performance management: key strategies and practical guidelines (2nd edition). London: Kogan Page.

Armstrong, M. (2001). Performance management: key strategies and practical guidelines (2nd edition). London: Kogan Page.

Barry, J., Chandler, J. \& Clark, H. (2001). Between the ivory tower and the academic assembly line. Journal of Management Studies, 38(1), 87-101.

Beavis, 0. H. (2003). Performance-based rewards for teachers: a literature review. For distribution at the $3^{\text {rd }}$ Workshop of participating countries on OECDS's activity attracting developing and retaining effective teachers, 4-5 June 2003. Athens, Greece.

Bernthal, P. R., Rogers, R. W. \& Smith, A. B. (2003). Managing performance: building accountability for organisational success. HR Benchmark Group, 4(2), 1-38.

Bourne, M., Kennerley, M. \& Franco-Santos, M. (2005). Managing through measures: a study of impact on performance. Journal of Manufacturing Technology Management, 16(4), 373-95.

Bourne, M., Mills, J., Wilcox, M., Neely, A. \& Platts, K. (2000). Designing, implementing and updating performance measurement systems. International journal of operations \& production management, 20(7), 754-71.

Brennan, J. \& Shah, T. (2000). Quality assessment and institutional change: Experiences from 14 countries. Higher Education, 40, 331-349.

Burney, L. L., Henle, C. A. \& Widener, S. K. (2009). A path model examining the relations among strategic performance measurement system characteristics, organizational justice, and extra- and in-role performance. Accounting,organizations and society, 34, 305-321.

Cameron, K. \& Quinn, R. E. (1999). Diagnosing and changing organizational culture: based on the competing values framework. MA: Addison-Wesley.

Chan, D. C. (2005). Core competencies and performance management in Canadian public libraries. Library Management, 2(3), 144-153.

Chan, L. L. M. (2004). In search of sustained competitive advantage: the impact of organizational culture, competitive strategy and human resource management practices on firm performance. The international Journal of Human Resource Management, 15(1),1-24.

De Waal, A. A. \& Counet, H. (2009). Lessons learned from performance management systems implementations. International Journal of Productivity and Performance Management, 58(4), 367390.

Decoene, V. \& Bruggeman, W. (2006). Strategic alignment and middle-level managers'motivation in a balanced scorecard setting. International Journal of Operations \& Production Management, 26(34), 429-448.

Den Hartog, D. N., Boselie, P. \& Paauwe, J. (2004). Performance Management: A model and research agenda, Applied Psychology: An International Review (In Press), 1-26.

Edward, E. L. (2003). Reward practices and PMS effectiveness: centre for effective organisations. University of California: Los Angeles. 
Franco-Santos, M., Lucianetti, L. \& Bourne, M. (2012). Contemporary performance measurement systems: A review of their consequences and a framework for research, 23(2), 1-85.

Fullan, M. \& Scott, G. (2009).Turnaround leadership for higher education. San Francisco: John Wiley \& Sons.

Harte, O. (1995). Coordinate governance some theory and implication. Economics Journal, 105, 678-689.

Hearn, J. C., Lewis, D. R., Kallsen, L., Holdsworth, J. M. \& Jones, L. M. (2006). Incentives for managed growth': A case study of incentive-based planning and budgeting in a large public research university. Journal of higher education, 77(2), 286-316.

Henson, S. L. (1994). No escape from judgement: appraisal and PRP in higher education. Occasional papers in organisational analysis, University of Portsmouth.

Hinkin, T. R. \& Schriesheim, A. (2004). If you do not hear from me, you know you are doing fine. Cornell hotel and restaurant administration quarterly, 45, 362-372.

Hough, J., Thompson, A. A., Strickland, A. J. \& Gamble, J. E. (2012). Crafting and executing strategy: creating sustainable high performance in South Africa. Management today.

Kaplan, R. S. \& Norton, D. P. (1996). Using the balanced scorecard as a strategic management system. Harvard business review, 75-85.

Matunhu, J. \& Matunhu, V. (2008). Performance management in parastatals: the cases of the Zimbabwe United Passenger Company and the National Railways of Zimbabwe. Africa insight, 38(1), 118135.

Meekings, A. (1995). Unlocking the potential of performance measurement: a guide to practical implementation. Public money \& management, 1-8.

Mendunca, M. \& Kanungo, R. N. (1996). Impact of culture on performance management in developing. International Journal of Manpower, 17(4/5), 65-75.

Meybodi, M. Z. (2010). The impact of just-in-time practices on consistency of benchmarking performance measures. $A C R, 18(1 \& 2), 73-88$.

Mondy, R. W. Noe, R. M. \& Premeaux, S. R. (2002). Human Resource Management (8 ${ }^{\text {th }}$ edn). Upper Saddle River, NJ: Prentice Hall.

Mweemba, R. S. \& Malan, J. (2009).The impacts of performance measurement on the quality of service delivery in the Zambian Public Service. Journal of contemporary management, 6, 36.

Ngcamu, B. S. (2012). The Inconsistencies on the Implementation of Performance Management System: An Employee Readiness Survey. Technics technologies education management, 7(3), 1394-1405.

Oakes, K. (2007). Performance management lacks consistency. T\&D.

Phiri, E. K. (1998). Performance appraisal of lecturers in the technical colleges in the North West Province. M-thesis. University of the North-West, Mmabatho.

Probst, M. T. \& Brubaker, T. L. (2001). The effects of job insecurity on employee outcome: cross-sectional and longitudinal exploration. Journal of occupational health psychology, 6(2), 139-159.

Republic of South Africa. (1999). Skills Levies No. 9 of 1999.Government Printers.

Republic of South Africa. (1998). Skills Development No. 97 of 1998.Government Printers.

Rose, R. C., Kumar, N., Abdullah, H. \& Ling, G. Y. (2008). Organizational culture as a root of performance improvement: research and recommendations. Contemporary management research, 4(1), 43-56.

Saunders, M., Lewis, P. \& Thornhill, A. (2007). Research Methods for Business Students. Forth Edition, Pearson Education Limited: England.

Schneiderman, A. (1999). Why balanced scorecards fail. Journal of Strategic Performance Measurement, special edition, 6-11.

Scholtes, P. R. (1999). Performance appraisal: state of the art in practice, in J. W. Smither (Ed). Personnel Psychology, 52(I), 177-81.

Scott-Ladd, B., Travaglione, A. \& Marshall, V. (2006). Causal inferences between participation in decision making, task attributes, work effort, rewards, job satisfaction and commitment. Leadership \& Organization Development Journal, 27(5), 399-414.

Sekeran, U. (1992). Research methods for business: a skill building approach, 2nd edition. New York: John Wiley and Sons.

Simon, R. (2001). Performance measurement \& control systems for implementing strategy-text \& cases. Engelwood Cliffs, NJ: Prentice-Hall.

Underhill, L. G. \& Bradfield, D. (1998). Introstat, Juta and Co. Ltd: Cape Town.

Walwy, D. (2008). An analysis of the performance management of South African higher education institutions. $S A J H E, 22(3), 708-724$.

Wilkinson, A. C. Fouries, M., Van der Westhuizen, L. J. \& Van Tonder, S. P. (2004). Performance management of academic staff in South African Higher Education, Centre for Higher Education Studies and Development, University of the Free State, Bloemfointein. 